\title{
A MÍDIA NAS ELEIÇÕES PRESIDENCIAIS BRASILEIRAS: UMA VARIÁVEL EM MUTAÇÃO? \\ Fernando Lattman-Weltman ${ }^{1}$
}

\begin{abstract}
Resumo: Apresentamos aqui um modelo que procura dar conta de variáveis essenciais para a compreensão da disputa de nossas eleições presidenciais $e$, mais especificamente, do papel particular exercido nelas pelo conjunto dos nossos principais meios de comunicação de massa. Ressalta de sua aplicação a autonomização relativa de variáveis clássicas de influência conjuntural sobre as eleições, como as expectativas acerca da economia e os índices de popularidade dos governantes, ao lado de uma convergência dos principais candidatos para o centro do espectro político, importante processo de estruturação do campo político brasileiro, e, por último, mas não menos importante, uma curiosa diminuição da influência relativa exercida pelos principais veículos de mídia em tais disputas.
\end{abstract}

Palavras-chave: Modelos de análise; Mídia; Eleições.

\begin{abstract}
We present a model that seeks to account for key variables to the understanding of Brazilian presidential elections and, more specifically, to the particular role played in it by our main means of mass communication. We emphasize the growing autonomy of classical and influential electoral variables, as the expectations about the economy and the popularity ratings of the government, along with a convergence of the leading candidates to the center of the political spectrum, which accounts for an important process structuring the Brazilian political field, and, last but not least, a curious decrease in the relative influence exerted by the major media groups sin such disputes.
\end{abstract}

Key words: Analytical models; Media; Elections.

Há cerca de pouco menos de uma década, mais precisamente ao analisar a campanha eleitoral de 2002 - que conduziu, afinal, Luis Inácio Lula da Silva, e o seu Partido dos Trabalhadores, ao controle do Poder Executivo federal brasileiro - elaborei um modelo tentativo que procurava dar conta de variáveis que me pareceram essenciais para a compreensão do processo de disputa de nossas eleições presidenciais e, mais especificamente, do papel particular exercido nelas pelo conjunto dos nossos principais meios de comunicação de massa ${ }^{2}$.

\footnotetext{
${ }^{1}$ Professor e pesquisador da Escola de Ciências Sociais, do Centro de Pesquisa e Documentação de História Contemporânea do Brasil, Cpdoc, Fundação Getulio Vargas, Rio de Janeiro. Email: Fernando.Lattman.weltman@fgv.br.

2 Essa primeira aproximação se encontra descrita em Lattman-Weltman (2004). Agradeço aos comentários dos colegas do Gt de "Comunicação \& Política", da Compós 2011, mas em especial ao relato crítico feito a meu modelo de análise conjuntural de eleições, por Luis Felipe Miguel e Flavia Birolli. Suas críticas foram essenciais à reformulação do modelo (e ao esforço por torná-lo mais defensável).
} 
Desde então, passadas mais duas eleições - com nova vitória de Lula em 2006, e agora de sua candidata, Dilma Rousseff - retomo aquele modelo, com pequenas, porém substanciais modificações, para novamente tentar compreender as principais características sistêmicas de nossas disputas para o mais importante cargo político do Estado, e novamente discutir a intervenção específica da mídia no processo.

Hoje, tal como naquela época, me interessa menos propor algum modelo exaustivo de explicação - ou ainda mais ambiciosamente, de previsão - de eleições presidenciais, do que me servir de tal ferramenta para compreender as principais mudanças históricas qualitativas do jogo político brasileiro, em permanente mutação.

Nesse sentido, o que ressalta da aplicação do modelo é o que poderia ser interpretado como constituindo a autonomização relativa de variáveis clássicas de influência conjuntural sobre as eleições - como as expectativas acerca da economia e os índices de popularidade dos governantes - ao lado de uma convergência dos principais candidatos para o centro do espectro político e, por último, mas não menos importante, uma curiosa diminuição da influência relativa exercida pelos principais veículos de mídia em tais disputas.

Se corretas tais hipóteses traduziriam importante processo de estruturação do campo político brasileiro, com significativas implicações para o reordenamento das principais clivagens ideológicas entre nós.

\section{Um modelo de variáveis eleitorais conjunturais}

Modelos de explicação e previsão de eleições presidenciais têm longa trajetória na tradição empírica da ciência política norte-americana.

A despeito das importantes diferenças que distinguem a experiência eleitoral da democracia naquele país da nossa, recente - em especial o fato de que as características bipartidárias do sistema norte-americano só se apresentam de modo similar para nós em nossos $2^{\text {os }}$ turnos - uma formulação de tais modelos que pode nos auxiliar é a fornecida por Abramovitz (1988). Ela nos interessa particularmente por sua extrema simplificação e parcimônia conceitual e teórica, e por se resumir a variáveis clássicas cuja importância, já há algum tempo, vem se manifestando entre nós: desempenho econômico e popularidade dos governantes ${ }^{3}$.

\footnotetext{
${ }^{3}$ Desenvolvido em diálogo com o modelo de Lewis-Beck \& Rice (1984), o de Abramovitz (1988) inclui ainda uma terceira variável: uma "taxa de desconto" de ocupação prévia da presidência pelo partido no poder; quanto mais longa essa ocupação, maior a probabilidade de o eleitorado desejar uma mudança.
} 
Com efeito, na primeira formalização do nosso modelo, levada a cabo para tentar fazer sentido das principais mudanças ocorridas entre as eleições presidenciais ocorridas no Brasil, desde o final do Regime Militar (1964-1985) até a vitória de Lula em 2002, trabalhei então com as seguintes variáveis:

a) Controle da economia: relativa ao sentido predominante no conjunto de expectativas compartilhadas pela sociedade com relação à economia do país e seu futuro imediato. Agora rebatizada, mais simplesmente, como "Expectativas econômicas";

b) Candidatura oficial: relativa à possibilidade, ou não, do governo em exercício apresentar como seu um candidato viável eleitoralmente. Após a aprovação, em 1997, da emenda constitucional que passou a permitir uma reeleição para os chefes do Poder Executivo, passaria a incluir, obviamente, a possibilidade de renovação do mandato para o próprio presidente em exercício. Substituída agora pela nomenclatura "popularidade do governo" (em exercício);

c) Ocupação do Centro: relativa ao modo de posicionamento dos principais competidores diante da posição estratégica representada em nosso sistema pelo Centro do espectro político-partidário-ideológico ${ }^{4}$. Foi acrescida agora da possibilidade não só de ocupação, mas também de efetiva disputa por essa posição;

d) Timing da mídia: referia-se ao modo e ao momento relativo em que os principais veículos de comunicação se inseriam deliberadamente na disputa eleitoral como atores engajados. Não por acaso foi a variável que mais necessitou de revisão em todo o modelo, pois que demonstrou não possuir mais qualquer poder discriminatório, uma vez que após o (duro) aprendizado proporcionado pela eleição extraordinária de Fernando Collor de Mello, em 1989, os meios nunca mais deixaram de se preparar e se antecipar para a definição das candidaturas presidenciais (entre outras). Por isso, agora a reformulei e passei a qualificar com ela o posicionamento médio dos principais veículos de comunicação brasileiros em relação ao (principal) candidato de situação.

\footnotetext{
${ }^{4}$ A questão do peso estratégico atribuído ao centro - e a seu(s) ocupante(s) - baseia-se em longa tradição de estudos eleitorais e partidários. Em linhas muito gerais, se refere, em $1^{\circ}$ lugar, a considerações teóricas acerca da racionalidade do voto do eleitor médio, não necessariamente alinhado previamente a este ou àquele candidato ou partido, e mais propenso a não possuir posições claras - nem "intensas", ou radicais - com relação a muito issues que dividem e polarizam a arena política. Daí a sua caracterização como eleitor de "centro", e cujo contingente de votos tenderia a ser elevado (e, portanto, decisivo). Em $2^{\circ}$ lugar, e consequentemente, à tendência dos grandes partidos competitivos a alargar - e frequentemente a diluir e/ou moderar - suas plataformas, de modo a assim maximizar seus apelos frente a estes eleitores de "centro". Ver a esse respeito, por exemplo, Downs (1999), e Kirchheimer (1966).
} 
Ora, aplicando-se então tais variáveis às conjunturas que presidiram todas as eleições presidenciais ocorridas no Brasil após a ditadura e a promulgação da nova Constituição, observamos no quadro abaixo os seguintes resultados:

\section{Quadro Geral de Desempenho de Variáveis de Conjuntura Eleitoral} Eleicões 1989-2010:

\begin{tabular}{|l|c|c|c|c|c|c|}
\hline Ano & $\begin{array}{c}\text { Expectativas } \\
\text { Econômicas }\end{array}$ & $\begin{array}{c}\text { Popularidade } \\
\text { do Governo }\end{array}$ & $\begin{array}{c}\text { Ocupação/ } \\
\text { Disputas } \\
\text { pelo Centro }\end{array}$ & $\begin{array}{c}\text { Posicionamento } \\
\text { Médio da } \\
\text { Mídia }\end{array}$ & $\begin{array}{c}\text { Sub- } \\
\text { Totais }\end{array}$ & Vencedor \\
\hline 1989 & -1 & -1 & -1 & -1 & -4 & $\mathrm{O}-2^{\mathbf{o}} \mathrm{T}$ \\
\hline 1994 & 1 & 1 & 1 & 1 & 4 & $\mathrm{~S}-1^{\mathbf{0}} \mathrm{T}$ \\
\hline 1998 & 0 & 1 & 1 & 1 & 3 & $\mathrm{~S}-1^{\mathbf{o}} \mathrm{T}$ \\
\hline 2002 & 0 & -1 & 0 & 0 & -1 & $\mathrm{O}-2^{\mathbf{o}} \mathrm{T}$ \\
\hline 2006 & 1 & 1 & 0 & -1 & 1 & $\mathrm{~S}-2^{\mathbf{0}} \mathrm{T}$ \\
\hline 2010 & 1 & 1 & 0 & -1 & 1 & $\mathrm{~S}-2^{\mathbf{o}} \mathrm{T}$ \\
\hline
\end{tabular}

1) Se em 1989 as expectativas econômicas eram francamente negativas - com as eleições transcorrendo em meio a uma crise praticamente hiperinflacionária -, em 1994 (Plano Real) e nas eleições que marcaram o final dos dois mandatos de Lula (2006 e 2010) as expectativas eram altamente positivas. O mesmo não se pode dizer dos anos de 1998 e 2002, quando havia sinais contraditórios no horizonte e, portanto, expectativas ambíguas e indefinidas. Daí as diferenças de notação: -1, 0 e 1;

2) Em correlação óbvia à variável anterior - mas ainda assim significativamente independente -, a popularidade dos governos em exercício variou do seguinte modo nas diferentes conjunturas: era negativa em 1989 (francamente) e em 2002 (não tanto); nos demais contextos, positiva (com variações de grau importantes; inclusive, certamente para mais em 1994). É curiosa a variação da avaliação dos governos de Fernando Henrique Cardoso (FHC) em seus dois momentos finais (1998 e 2002), e o modo como essa variável se autonomiza relativamente em contextos de nebulosidade na esfera das expectativas econômicas (a rigor, como iremos propor adiante, essa autonomização da variável "popularidade" - não somente diante das conjunturas econômicas - pode ser um dos traços mais importantes da evolução atual de nosso sistema);

3) A ocupação, ou disputa pelo Centro, também vem evoluindo de modo bastante expressivo em nossas eleições: se em 89 abriu-se aqui um verdadeiro vácuo - dando margem a uma polarização que acabou sendo vencida, à direita, por Collor ${ }^{5}$ - em 94 e em 98 o candidato do governo Itamar Franco (1992-1995), FHC, reinou aqui, praticamente sem rival

\footnotetext{
${ }^{5}$ Ver Lattman-Weltman et al (1994).
} 
ou contestação. Foi somente em 2002 que o principal candidato de oposição à época, Lula, dirigiu-se para cá, e onde disputou a posição com seus principais adversários, inclusive o candidato da situação (José Serra). Já como candidato situacionista à reeleição, Lula repetiu a dose contra Geraldo Alckmin em 2006, tendo Dilma Rousseff, candidata do Governo Lula (2003-2011) enfrentado José Serra e Marina Silva nesta mesma arena, nas eleições de 2010. Por isso, desde 2002, a notação aqui é nula, a indicar assim certa neutralização conjuntural dessa variável ${ }^{6}$;

4) Finalmente, a última variável do modelo - o posicionamento médio da mídia frente ao (principal) candidato de situação - apresenta uma evolução que, em si mesma, poderia não guardar maior significado do que registrar uma simples variação conjuntural em termos do eventual posicionamento da mídia frente aos principais candidatos de situação e oposição: ora a favor de um, ora do outro (ou em relativa neutralidade a ambos). Com efeito, fosse a mídia, de fato, tão politicamente irrelevante ou neutra, quanto apregoam visões normativas, digamos, mais ortodoxas, sobre o seu lugar na política, não haveria nada a destacar (a rigor, nem poderíamos incluí-la aqui como variável do modelo). No entanto, mesmo que estejamos aqui diante de uma mudança, ou tendência que aponte justamente no sentido da perda de influência eleitoral relativa da mídia - já que se em 1989, 1994 e 1998 ela se posicionou a favor dos candidatos, da oposição ou da situação, que efetivamente venceram, a partir de 2002 não houve mais tal correlação positiva - creio que seria, no mínimo, grave precipitação, a partir de tais indícios, descartar a hipótese de permanência de influência específica por parte dos principais meios de comunicação em nossas eleições presidenciais (deixarei esse ponto central do argumento para logo adiante).

\section{Continuemos nossa análise, portanto:}

Tomando-se o quadro como um todo, não se pode deixar de mencionar a correlação entre os subtotais negativos, de 1989 (-4) e de 2002 (-1), com o fato de que, tal como ilustra a última coluna, tais eleições terem sido vencidas por candidatos de oposição, e nos $2^{\text {os }}$ turnos $\left(\mathrm{O}-2^{\mathrm{o}} \mathrm{T}\right)^{7}$. De um mesmo modo, mas em sentido oposto, observam-se as vitórias dos candidatos de situação, quando os subtotais das quatro variáveis são positivos: quando

\footnotetext{
${ }^{6}$ Digo conjuntural porque esta é uma variável intrinsecamente dependente das escolhas estratégicas dos principais candidatos em cada eleição. E nada nos garante que nos próximos pleitos não possamos ter candidatos fortes atuando preferencialmente nas margens do sistema. Não creio que isso seja muito provável - nem muito menos desejável. Mas quem pode saber?

${ }^{7}$ Talvez se pudesse teorizar a respeito das diferenças de resultado negativo entre uma e outra eleição (-4 e -1$)$ : enquanto na primeira a oposição ao governo se diversificou em várias candidaturas competitivas - tendo as duas mais bem sucedidas disputado entre si no $2^{\circ}$ turno - sem que a situação pudesse ser de fato representada com chances reais, na segunda eleição a oposição precisou derrotar forte candidato situacionista, por assim dizer, em seu terreno (e também no $2^{\circ}$ turno).
} 
atingiram o menor valor positivo (1), observou-se a vitória da situação $\left(\mathrm{S}-2^{\circ} \mathrm{T}\right)$ no $2^{\circ}$ turno (2006 e 2010); quando a soma positiva foi maior, já no $1^{\circ}$ turno ( $\left.\mathrm{S}-1^{\circ} \mathrm{T}\right)$ : 1994 (4) e 1998 (3).

Assim, temos, para cada uma das cinco eleições presidenciais do Brasil pós-ditadura, quase que um contexto peculiar e específico, com importantes diferenças, tanto de grau quanto mais propriamente de natureza (com exceção, é claro, das duas últimas, que apresentam pouca variação significativa entre si) ${ }^{8}$ :

a) Em 1989, Collor se elegeu em $2^{\circ}$ turno, confirmando o favoritismo que construíra de modo surpreendente, ao longo daquela campanha, apoiado então pelos principais meios de comunicação do país, em contexto de grave crise econômica, opondo-se ao impopular governo de José Sarney, e num pleito marcado pela polarização entre a esquerda e a direita, sem nenhuma candidatura situacionista competitiva ao centro. Além da dimensão econômica, excepcionalmente ruim naquela conjuntura, há que se mencionar como específico daquela especialíssima eleição o favoritismo ímpar de que gozaria então qualquer candidato de oposição naquele momento (inclusive junto à mídia). Mas o mais importante - para dar a 1989 o seu feitio único e imprevisível - parece ter sido o vácuo deixado ao centro do espectro político e ideológico. Foi aí que cresceram tanto as candidaturas, se não antissistêmicas (ou aparentemente antissistêmicas) de Collor e Lula, pelo menos marginais em relação aos partidos mais fortes à época ${ }^{9}$. Assim como o possível aumento do peso relativo da mídia e do uso do HPEG;

b) Já nas vitórias consecutivas de FHC, para além das óbvias similitudes, há que se mencionar as mudanças importantes que nosso modelo, com sua simplicidade, pode ocultar: se a decisiva novidade da ocupação do centro pelo principal candidato situacionista marca historicamente o advento da estratégia que uniu então o Partido da Social Democracia Brasileira (PSDB) ao Partido da Frente Liberal (PFL) (e a outras siglas menores), as diferenças em termos de expectativas econômicas afetaram sobremaneira os perfis tanto da popularidade da situação, quanto o conteúdo do apoio da mídia ao candidato do governo em cada pleito: em 1994 o sucesso do Plano Real consagrou, ao mesmo tempo, o governo Itamar Franco - em seu surpreendente final - o seu candidato, FHC, e, acima de tudo, o acerto de uma articulação que envolveu tanto uma estratégia técnica (a da paulatina conversão e adesão

\footnotetext{
${ }^{8}$ À parte, talvez, o "pequeno detalhe" da ausência de uma candidatura pessoal de Lula em 2010 (pela 1" vez, desde a redemocratização).

9 A caracterização dos "partidos antissistema" foi cunhada por Sartori (1982), e se refere a partidos cuja plataforma se caracteriza por questionar - e eventualmente solapar - as próprias bases éticas e jurídicas que fundamentam a competição política democrática, tornando-se assim frequentemente irresponsáveis (quando não subversivos).
} 
dos principais agentes econômicos ao timing do Plano), quanto outra, mais propriamente política e eleitoral, em torno do candidato ideal e sua agenda de reformas ${ }^{10}$. Já em 1998, o contexto econômico nebuloso - com graves ameaças pairando no cenário internacional, e os primeiros desgastes do Plano Real - não foi suficiente para afetar, de modo decisivo, a popularidade de que seguia gozando o $1^{\circ}$ governo FHC. Pelo contrário, a manutenção do verdadeiro monopólio do centro, conservado pelo então presidente/candidato, de par com o apoio inquestionado, e inquestionável, que seguiu recebendo dos principais meios de comunicação, permitiu a FHC até mesmo favorecer-se da conjuntura econômica potencialmente adversa: quem mais poderia conduzir o país com segurança em meio à tormenta que se anunciava, sem o risco de retrocessos, sobressaltos e, dando continuidade ao programa de reformas estruturais do nosso Estado $?^{11}$

c) Não surpreende, portanto, que vista agora, a pequena distância, a eleição de 2002 destaca-se como momento de grande virada nas coordenadas gerais do jogo político e eleitoral brasileiro. Um rápido olhar nos dados de nosso quadro leva a pensar que, com efeito, a vitória de Lula no $2^{\circ}$ turno das eleições de 2002 foi o resultado de uma conjugação singular de todas as nossas variáveis: a articulação de um contexto novamente contraditório e preocupante de expectativas econômicas, de par com um governo com popularidade em queda - ademais de não poder contar novamente com a presença específica de FHC no pleito, e sofrendo o praticamente inédito desgaste de oito anos de exercício ${ }^{12}$-, mas cujas variáveis especificamente político-partidárias estavam mais bem situadas no modo como a estratégia eleitoral de Lula o trouxe, pela primeira vez, para o centro do espectro político-ideológico que ele, de fato, disputou e conquistou, frente a todos os adversários efetivos -, movimento este que, também não por acaso, acabou sendo muito bem recebido pela grande mídia em sua cobertura. A rigor, pode-se dizer que 2002 foi a única eleição em que esta instituição não assumiu nenhuma posição relevante diante dos candidatos principais ${ }^{13}$.

d) A partir de tais inflexões políticas - disputa partidária pela ocupação do centro (com sua consequente neutralização como variável decisiva) e diminuição (ou redefinição) da influência midiática -, operadas em 2002, passam a ressaltar, em nosso modelo, as similitudes

\footnotetext{
${ }^{10}$ Ansiada e caracterizada, em suas linhas gerais, desde o fiasco do governo Collor (Lattman-Weltman, 2004).

${ }^{11}$ Aliás, para que mesmo emendamos a Constituição e abrimos a possibilidade de reeleições no Poder Executivo, pela primeira vez em mais de cem anos de história republicana?

${ }^{12}$ Não por acaso, como vimos, a principal inovação introduzida por Abramovitz (1988) em seu modelo de previsão de resultados para eleições presidenciais norte-americanas, em relação a outros que lhe serviram de base.

${ }^{13}$ Como disse anteriormente (Lattman-Weltman, 2004), isso não exclui as exceções - como a revista Veja - nem eventuais quebras desse padrão, como na cobertura negativa dada, em momentos decisivos, a candidatos como Ciro Gomes. Mas ambos os casos são, a meu juízo, muito mais exceções à regra.
} 
entre 2006 e 2010: vitórias da situação - com e sem o próprio Lula - no $2^{\circ}$ turno, em contextos de otimismo econômico e alta popularidade governamental. Mesmo a variável de Abramovitz (1988) - a taxa de desconto do desgaste natural de administrações longas parece ter sido perfeitamente neutralizada, nas eleições de 2010, em função do alto desempenho da situação nas variáveis mais tradicionais.

Na verdade, a chegada de Lula e do PT ao poder, mas acima de tudo o sucesso obtido por essa administração, tanto no que se refere à recuperação positiva dos indicadores econômicos, quanto na consequente popularidade que passou a granjear, implicou em muitas outras alterações significativas na nossa vida política e na estrutura das disputas eleitorais pela presidência.

Embora não seja aqui o espaço adequado para se fazer tal balanço, não se pode deixar de mencionar o fato de que o deslocamento de um novo e poderoso grupo político, das margens para o centro do espectro ideológico, e daí para o centro do poder - já que mesmo que a retórica de esquerda do PT tenha sido mantida, em certos setores do próprio governo Lula, a prática da administração, em especial na esfera econômica, seguiu fielmente os compromissos assumidos na campanha de 2002, com a famosa "carta aos brasileiros" -, forçou o realinhamento de todo o campo político nacional. Incluídas aí, é claro, tanto as oposições partidárias quanto as informais e mais amplas, na sociedade brasileira como um todo.

Ou seja: a ocupação - que a essa altura pode ter se tornado, de fato, não competitiva do centro, pelos principais candidatos à presidência da República, a começar pela situação petista, desloca a estrutura ideológica do nosso sistema para as margens do embate direita/esquerda, fazendo com que outras agendas, outros issues, tornem-se objeto de manipulação e investimento discricionário, para efeitos de confrontação política e eleitoral.

Assim, não é de surpreender que temas alheios ao debate macroeconômico - que dominaram inegavelmente as agendas das campanhas até 2002, inclusive - tenham se tornado prioritários em 2006 e, ainda mais, em $2010^{14}$. Com efeito, se em 2006 a agenda da oposição - incluída aí a grande mídia - repetiu à exaustão o velho tema da corrupção ${ }^{15}$, no ano de Dilma a agenda se diversificou ainda mais: temas como aborto, religiosidade, ecologia,

\footnotetext{
${ }^{14}$ Com a possível exceção da questão específica dos gastos públicos - estratégica para uma oposição que enfrentava a poderosa candidatura da principal administradora da situação - e, em menor intensidade, da carga tributária, praticamente não houve debate sobre a economia. Qual dos dois candidatos oposicionistas principais teria interesse - e real liberdade de manobra - para enveredar por esse caminho?

${ }^{15}$ Diga-se de passagem, numa chave eleitoralmente mais interessante do que a manipulada por Collor, em 1989, pois que agora, em 2006, a situação era o adversário a ser fustigado com o tema (e não um governo em descrédito e fora do páreo).
} 
liberdade de expressão, etc., constituíram-se em novas barricadas e mecanismos de diferenciação crítica entre candidatos, partidos e alianças. E em novas arenas para o exercício - ou melhor, para uma tentativa desesperada de exercício - de uma influência específica que outrora parece ter sido tão crucial: a influência da mídia nas eleições.

\section{A estruturação do sistema político e a mídia como variável dependente}

Como disse antes, minha preocupação não é propriamente demonstrar a capacidade explicativa e/ou preditiva do modelo, mas sim utilizá-lo para chamar a atenção para as relações entre as variáveis e sua evolução histórica.

Nesse sentido, como já sugerido, há que se destacar o modo como a $1^{\mathrm{a}}$ variável, sobre as expectativas com relação à economia, confirma a sua importância, tal como sempre destacado pela literatura sobre resultados eleitorais em modernas democracias competitivas: é difícil vencer uma candidatura situacionista quando as coisas vão bem. E o reverso parece operar sem maiores surpresas, no caso oposto (apesar de que, felizmente, desde que retornamos à democracia, só passamos pela experiência de eleições em contextos de grave e inequívoca crise econômica uma vez; e por todos os motivos, não temos nenhuma saudade de tal conjuntura). Quando a situação é incerta, porém, o peso relativo das demais variáveis parece crescer. Foi o que vimos em 1998 e em 2002: aqui certamente o fator "popularidade" do governo foi o que mais pesou. Mas as estratégias dos candidatos principais com relação ao centro político e, por último, mas não menos importante, o modo como a mídia se posicionou - e, certamente, como influenciou a construção da própria narrativa dos riscos e possibilidades da conjuntura econômica e das alternativas políticas a ela - tiveram também a sua decisiva parcela de responsabilidade pelos resultados finais (e partidariamente contraditórios) destas duas campanhas.

Por sua vez, embora certamente influenciada pelas expectativas econômicas, a variável mais independente de todas, a que se refere à popularidade relativa do governo em fins de exercício, é a única que guarda uma correlação sempre positiva com relação ao destino final das eleições: se vitória da situação, ou da oposição. Conquanto possa parecer óbvio - que governos populares sejam reeleitos ou elejam seus candidatos - é importante ressaltar a autonomia dessa variável quando ela se mantém a despeito até do posicionamento médio da mídia (ou seja: exatamente como se deu nas últimas duas eleições). Sendo esta, também, uma variável classicamente utilizada para a explicação e a previsão de eleições - com grande 
sucesso em contextos históricos marcados pela rotinização dos procedimentos democráticos competitivos - não deixa de ser importante a constatação de sua independência, ou talvez crescente independência, também no Brasil. E menos importante do que atentar para como nossas eleições presidenciais possam estar ficando cada vez mais parecidas com a de outras democracias, mais velhas e experientes, é o fato de que os graus de popularidade de uma administração, por si só, são importantes indicadores acerca da relação que, de um modo ou de outro, os soberanos - os eleitores - entretêm com seus representantes. Como reza a boa tradição madisoniana - a de que governos efetivamente republicanos são aqueles em que os governantes são, de algum modo, controlados por seus governados ${ }^{16}$ - a influência praticamente independente com que a popularidade define o futuro de situações e oposições é um índice claro da chamada accountability vertical e, portanto, da efetiva representatividade dos governos democráticos ${ }^{17}$.

Quanto à variável relativa à ocupação ou às disputas pelo centro político, creio não ser preciso um grande esforço de memória, ou de conhecimento histórico sobre a democracia brasileira, para se ter uma noção da importância tanto de seu papel nas nossas disputas políticas, quanto do significado histórico da evolução recente da variável nas nossas eleições presidenciais. Numa república marcada por rupturas institucionais e longos períodos autoritários, é digno de nota o modo como a ocupação e, portanto, também a valorização do centro torna-se não somente um fator de equilíbrio das próprias instituições democráticas ${ }^{18}$, mas também um objetivo a ser perseguido como pré-condição para o sucesso - se não a própria viabilidade - de estratégias reais de conquista do poder, pelas vias constitucionais. Torna-se de tal modo imprescindível - senão consensual - que, inclusive, perde importância relativa como variável definidora dos resultados eleitorais para a presidência. Uma perda de importância relativa que, no entanto, pode implicar o aumento de certo equilíbrio das disputas e a condução da necessidade de decisões somente em $2^{\circ}$ turno (de fato, a neutralização relativa dessa variável nas últimas três eleições coincidiu com o prosseguimento dos pleitos até seu último momento possível). Somente o futuro poderá confirmar, contudo, tal tendência. De qualquer maneira, a evolução da agenda eleitoral - principalmente na última eleição - em torno não mais do privilégio estratégico ("tradicionalmente moderno") conferido aos temas macroeconômicos ou mesmo socioeconômicos, mas sim a uma pauta predominantemente

\footnotetext{
${ }^{16}$ Sobre a teoria republicana de Madison (e dos demais "federalistas"), ver Madison et al (1993). Sobre sua importância para a teoria democrática contemporânea, ver Dahl (1989).

17 Sobre as distinções entre accountabilities vertical e horizontal, ver O,Donnell (1999) e Przeworski, Manin \& Stokes (1999).

${ }^{18}$ Como demonstrou Santos (2003) em sua análise da crise de 1964.
} 
cultural ("pós-modernidade", afinal?), pode ser índice de uma alteração histórica mais profunda nas clivagens ideológico-políticas do país (a conferir).

Finalmente, no que diz respeito à nossa última variável - a da influência midiática, por conta de seu favoritismo a esse ou aquele candidato - mesmo que posta em cheque pelos últimos dados e resultados, é preciso ter aqui uma série de cuidados. Por um lado, é totalmente inegável o simples fato de que embora a influência específica da mídia possa ter sido importante, se não mesmo decisiva, em 1989, 1994 e 1998, e se em 2002 sua relativa neutralidade possa ser, ainda mais discutivelmente, arrolada como um dos fatores a contribuir para que, afinal, Lula e o PT chegassem ao Planalto, é certo que nas últimas duas eleições o mainstream da atuação midiática se posicionou em sentido oposto ao da maioria do eleitorado: combateu fortemente as candidaturas de Lula e de Dilma e não pode impedi-las de vencer.

É justamente por isso que alguns analistas têm questionado consistentemente a suposta influência da mídia e seus "formadores de opinião" nos rumos das eleições presidenciais. Um dos melhores exemplos dessa produção se encontra no interessantíssimo artigo de Marcos Coimbra, intitulado “A mídia teve algum papel durante o processo eleitoral de 2006?" (2007), e no qual o analista político do Instituto Vox Populi argumenta que, nas eleições de 2006, a mídia tentou, sem sucesso, exercer influência sobre um eleitorado já previamente estruturado, em suas linhas gerais, e cujo veredicto se deu sem surpresas, reelegendo Lula. Em poucas palavras, a explicação de Coimbra para essa pouca influência se deve aos seguintes fatores: ao longo das últimas duas décadas de democratização e prática ininterrupta do ato de votar deuse também o aumento dos níveis de escolaridade do eleitor brasileiro médio, o seu envelhecimento médio, a sua obtenção de maior experiência eleitoral. Todos esses fatores, segundo o autor, tornariam esse mesmo eleitor médio mais seguro de si, menos suscetível às piruetas do marketing eleitoral, mas acima de tudo também a possíveis ênfases, exageros, ou mesmo manipulações da cobertura jornalística. Isto teria se dado, inclusive, no modo como teria sido absorvida pelo eleitorado a exaustiva cobertura, um ano antes das eleições, do escândalo do "mensalão" e seus desdobramentos (escândalo este que, acrescento eu, foi o principal responsável não só pela mudança de postura da maior parte da grande mídia diante do governo Lula, mas também pelas novas apostas feitas pela oposição - nos partidos e fora deles - com vistas a derrotar o então presidente e o PT).

O mais importante aspecto da argumentação de Coimbra, porém, parece-me ser o que ele chamou de "estruturação" do campo político brasileiro, operada, nesse começo de século, pela presente constante de Lula nas disputas presidenciais e, last but not least, sua chegada e 
bem sucedida passagem pelo poder. Assim, ao iniciar-se a campanha de 2006, prossegue o autor, o eleitorado já se dividia entre o setor pró-Lula, o anti-Lula, e o que ele chamou de "independentes". A análise pormenorizada da evolução das pesquisas de opinião permite a Coimbra demonstrar o caráter praticamente monótono da campanha daquele ano, com seu desenlace previsível desde o primeiro momento.

Tendo a concordar com quase toda a análise, inclusive, em especial, com as hipóteses sobre o papel atribuído a Lula na estruturação do campo político.

Devo, porém, suavizar o teor da provocação constituinte do artigo - de que a mídia não influencia - contrapondo apenas dois argumentos (que, a rigor, não contradizem os dados trazidos pelo autor):

Se não foi, de fato, capaz de alterar os rumos daquela eleição (assim como a de 2010) a mídia pode, sim, ter tido influência ao menos no impedimento da vitória de Lula em 2006 (e de Dilma, em 2010), já no $1^{\circ}$ turno. Os dados de Coimbra para o ano da reeleição de Lula não deixam de apontar para os possíveis efeitos da cobertura do chamado escândalo dos “aloprados" na reta final do $1^{\circ}$ turno de $2006^{19}$. De modo muito similar - ou pelo menos, com um timing muito próximo - também o favoritismo de Dilma Rousseff no $1^{\circ}$ turno das eleições de 2010 parece ter sido abalado pela exposição exaustiva de denúncias envolvendo sua substituta na Casa Civil do Governo Lula, Erenice Guerra. Não tenho comigo, para a última eleição, dados tão precisos quanto os do próprio artigo de Coimbra, para 2006. Nem pretendo fazer de tais casos isolados evidências incontestes. Mas creio que, sem prejuízo dos elementos centrais de seu argumento - que, de novo, me parecem muito plausíveis - eles não deixam de apontar para a possibilidade, ainda, de uma influência relativa e significativa da parte da mídia. Principalmente, junto àquela parcela de eleitores que ele chama de "independentes": os que podem ou não votar na situação ou na oposição.

O mais interessante para mim, porém, é o fato de que assim como podem ter exercido alguma influência conjuntural importante, mesmo que limitada (e dependente frente às outras variáveis) - como nos casos que antecederam imediatamente os $1^{\text {os }}$ turnos das últimas duas eleições - os meios de comunicação exercem outras formas de influência que, de um modo ou de outro, e às vezes até contraditoriamente, afetam as estratégias e, conseqüentemente, os resultados eleitorais. Um exemplo é fornecido pela própria análise de Coimbra: a cobertura do “mensalão" no ano que antecedeu as eleições de 2006.

\footnotetext{
${ }^{19}$ Como o leitor há de se lembrar, os "aloprados" seriam militantes do PT que teriam sido flagrados tentando comprar, com dinheiro vivo e suspeito, dossiês para utilização contra a candidatura de José Serra, do PSDB, ao governo do estado de São Paulo. O caso foi fartamente explorado pelas revistas, jornais e televisões à época.
} 
A $1^{\text {a }}$ hipótese aqui é a de que ao explorar exaustivamente o assunto - tal e qual um estranho partido político -, dia a após dia, dando à cobertura, inclusive, um tom exagerado de cruzada moralista, a mídia, como um todo, pode ter contribuído para a construção de uma narrativa simplista segundo a qual todos os quadros políticos e instituições do Estado seriam igualmente corruptos. Descrevendo assim, como se diz, uma noite em que todos os gatos são pardos, e desse modo, paradoxalmente, retirando à temática da corrupção todo o seu gume discricionário em termos político-partidários: quer dizer, tornando-o incapaz de permitir, ao eleitor/leitor/ouvinte/telespectador/ internauta, claramente distinguir um candidato, ou partido, do outro. Num registro narrativo como esse, com efeito, a melhor opção para o eleitor racional, mesmo aquele que segue valorizando o compromisso ético dos candidatos como variável de peso para sua escolha - e doravante convencido da corrupção generalizada no mundo político - é votar instrumentalmente no candidato, ou partido, cuja ação mais lhe beneficia (seja tal benefício obtido de modo corrupto, ou não).

A $2^{\mathrm{a}}$ e última hipótese - em estrita relação com a anterior, mas sem o seu caráter protopartidário - é a de que muito antes de assim intervir e influenciar os rumos das disputas eleitorais, ao se concentrar obsessivamente sobre determinados assuntos, aos quais confere o valor de servir ao suposto interesse público, a mídia atende a suas próprias motivações internas, à satisfação de suas próprias necessidades institucionais autoimpostas de construção e manutenção de uma autoimagem de superioridade ética/política. Imagem esta que obviamente se mantém e se reproduz em estrita relação com a (re)produção da (auto)imagem do seu próprio público, leitor/ouvinte/ telespectador/internauta, identificado ao veículo, em sua alta missão civilizatória. Uma cumplicidade que se autorreproduz assim - de modo eventualmente crucial tanto para a sobrevivência econômica quanto para o prestígio institucional da mídia - e para a qual, inclusive, a eventual derrota eleitoral é, na verdade, assunto secundário (embora tantas vezes recebida com amargo ressentimento).

Seja como for, o que importa é que em qualquer uma dessas duas hipóteses o resultado é o mesmo para a mídia enquanto ator político: a construção de sua própria perda de influência eleitoral ${ }^{20}$.

\footnotetext{
${ }^{20} \mathrm{O}$ que, afinal de contas, venhamos e convenhamos, pode ser até mesmo um preço bem baixo, se obtido em troca da reafirmação - mesmo que politicamente ressentida - de um elevado sentimento de superioridade ética.
} 


\section{Fontes Bibliográficas:}

ABRAMOWITZ, Alan I. An improved model for predicting election outcomes. In: PS: Political Science, Fall, 1988.

COIMBRA, Marcos. A mídia teve algum papel durante o processo eleitoral de 2006?. In: V.A.Lima (org.), A mídia nas eleições de 2006. São Paulo: Perseu Abramo, 2007.

DAHL, Robert. Um prefácio à teria democrática. Rio de Janeiro: J. Zahar, 1989.

DOWNS, Anthony. Uma teoria econômica da democracia. São Paulo: Edusp, 1999.

KIRCHHEIMER, Otto. The transformation of the western European party systems. In: J. La Palombara \& M. Weiner (eds.). Political parties and political development. New Jersey: Princeton University Press, 1966.

LATTMAN-WELTMAN, Fernando. "Economia simbólica, aprendizado político e institucionalização da mídia no Brasil”. In: Lusotopie, Paris, 2004.

CARNEIRO, J.A.D., \& RAMOS, P.A. A imprensa faz e desfaz um presidente. Rio de Janeiro: Nova Fronteira, 1994.

LEWIS-BECK, Michael S. \& RICE, Tom W. "Forecasting presidential elections: a comparison of naïve models". In: Political Behaviour, 6 (1), 1984.

MADISON, J., HAMILTON, A. \& JAY, J. Os artigos federalistas 1787-1788: edição integral.Rio de Janeiro: Nova Fronteira, 1993.

O'DONNELL, Guilhermo. "Horizontal accountability in new democracies".In: A. Schedler, L. Diamond \& M.F. Plattner (eds.). The self-restraining state: power and accountability in new democracies. London: Lynne Rienner, 1999.

PRZEWORSKI, A., MANIN, B., \& STOKES, S. (eds.). Democracy, accountability and representation. Cambridge: Cambridge University Press,1999.

SANTOS, Wanderley Guilherme dos. O cálculo do conflito: estabilidade e crise na política brasileira.Rio de Janeiro/Belo Horizonte: Iuperj/UFMG, 2003.

SARTORI, Giovanni. Partidos e sistemas partidários. Rio de Janeiro/Brasília: Zahar/UnB, 1982. 